\title{
(TRANS)FORMAÇÃO DA DOCÊNCIA: CONTRIBUIÇÕES DAS EXPERIÊNCIAS DE VIDA À FORMAÇÃO INICIAL DE PROFESSORES
}

\author{
TEACHING (TRANS) FORMATION: CONTRIBUTIONS OF LIFE EXPERIENCES TO \\ INITIAL TEACHER TRAINING
}
(TRANS)FORMACIÓN DE LA DOCENCIA: CONTRIBUICIONES DE VIDA EN LA FORMACÍON INICIAL DE PROFESORES

Vanessa Therezinha Bueno Campos ${ }^{1}$; Fernanda Duarte A. Silva ${ }^{2}$

\begin{abstract}
RESUMO
Esse relato de uma experiência realizada na disciplina Didática Geral, oferecida aos cursos de licenciatura na Universidade Federal de Uberlândia, objetiva compreender o universo dos processos de formação inicial de professores a partir da autoformação. A proposta do Projeto de Docência é apresentada no início do semestre enquanto instrumento reflexivo, visando à assunção da profissão docente. Constatamos nos primeiros momentos que a elaboração de tal documento provoca resistências; entretanto, uma vez superadas as dificuldades iniciais, o mergulho em busca de si é inevitável - os estudantes descobrem que o sentido do aprendizado está no próprio viver. Apesar de a proposta de desenvolvimento do Projeto de (trans)formação para a docência ser comum às diferentes turmas, em semestres variados, a produção de cada uma delas apresenta resultados singulares. A ênfase está no reconhecimento tanto dos saberes formais externos aos indivíduos quanto dos saberes subjetivos/não formalizados que as pessoas transportam consigo, os quais são tecidos em suas experiências de vida, de acordo com contextos socioculturais diversificados. Depreendemos que as narrativas (auto)biográficas, ao longo do processo de formação de professores, fornecem elementos valiosos para a autorreflexão de alunos e professores, além de possibilitarem a intervenção problematizadora do formador sobre concepções, crenças e saberes dos licenciandos em relação à docência, ao promoverem a sua (trans)formação.
\end{abstract}

PALAVRAS-CHAVE: Docência. Formação de Professores. Educação.

\section{ABSTRACT}

This experience report in General Didactics, offered to undergraduate courses at Universidade Federal de Uberlândia, aims to understand the universe of the initial teacher training process from self-training. The proposal of the Teaching Project is presented at the beginning of the semester as a reflective instrument, aiming at the assumption of the teaching profession. In the first moments, we find that the elaboration of this document provokes resistance; however, once the initial difficulties have been overcome, the diving for self-seeking is inevitable - students discover that the sense of learning is in their own lives. Although the development proposal of the Teaching Project is common to different classes and in various semesters, the production of each of them presents unique results. The emphasis is on the recognition both of the formal knowledge external to the individuals and subjective/non-formalized knowledge that people carry with them, which are woven into their life experiences, according to different sociocultural contexts. We argue that the (auto)biographical narratives, throughout the teacher training process, provide valuable elements for the self-reflection of students and teachers, as well as making possible the problematizing intervention of the trainer on conceptions, beliefs and knowledge of graders in relation to the teaching when promote their (trans)formation.

\footnotetext{
${ }^{1}$ Pós-doutorado em Educação - Universidade de São Paulo (USP) - São Paulo, SP - Brasil. Professora Associada da Faculdade de Educação e do Programa de Pós-Graduação - Universidade Federal de Uberlândia (UFU) Uberlândia, MG - Brasil. E-mail: vbcampos@ufu.br

2 Doutorado em Educação - Universidade Federal de Uberlândia (UFU) - Uberlândia, MG - Brasil. Professora Adjunta do Instituto de Ciências Humanas do Pontal (ICHPO) - Universidade Federal de Uberlândia (UFU) Uberlândia, MG - Brasil. E-mail: fernandaduarte@ufu.br
}

Submetido em: 02/10/2017 - Acesso em: 28/06/2018

(C) ETD-Educação Temática Digital Campinas, SP v.21 n.1 $\quad$ p.242-258 jan./mar. 2019 
KEYWORDS: Teaching. Teacher training. Education.

\section{RESUMEN}

Ese relato de una experiencia realizada en la disciplina Didáctica General, ofrecida a los cursos de licenciatura en la Universidad Federal de Uberlandia, objetiva comprender el universo de los procesos de formación inicial de profesores a partir de la autoformación. La propuesta del Proyecto de Docencia es presentada al inicio del semestre como un instrumento reflexivo, pretendiendo la asunción de la profesión docente. Constatamos en los primeros momentos que la elaboración de tal documento provoca resistencia; sin embargo, una vez superadas las dificultades iniciales, la profundización en busca de si es inevitable - los estudiantes descubren que el sentido del aprendizaje esta en el proprio vivir. A pesar de que la propuesta de desarrollo del Proyecto de (trans)formación para la docencia es común a las diferentes clases, en semestres variados, la producción de cada una de ellas presenta resultados singulares. El énfasis está en el reconocimiento tanto de los saberes formales externos a los individuos como a los saberes subjetivos/no formalizados que las personas transportan consigo, los cuales son tejidos en sus experiencias de vida, de acuerdo con los contextos socioculturales diversificados. Inferimos que las narraciones (auto)biográficas, a lo largo del proceso de formación de profesores, proporcionan elementos valiosos para la autorreflexión de alumnos y profesores, además de posibilitar la intervención problematizadora del formador sobre concepciones, creencias y saberes de los licenciados con relación a la docencia, al promover su (trans)formación.

PALABRAS-CLAVE: Docencia. Formación de Profesores. Educación.

\section{INTRODUÇÃO}

Sim, sou eu, eu mesmo, tal qual resultei de tudo Quanto fui, quanto não fui, tudo isso sou

Quanto quis, quanto não quis, tudo isso me forma Quanto amei ou deixei de amar é a mesma saudade em mim.

(Álvaro Campos, 1944)

Formar-se, na perspectiva assinalada no fragmento do poema de Álvaro Campos, supõe troca, experiência, interações sociais, aprendizagem, um sem fim de relações que suscita reflexões sobre a formação e o desenvolvimento da profissão docente. Devemos considerar a formação assim como a educação, tal como propõe Freire (1991, p. 21-22), é "um ato político", pois:

Não há prática educativa indiferente a valores. Ela não pode ser indiferente a um certo projeto, desejo ou sonho de sociedade. Ninguém é educador por simples acaso. Ninguém forma por formar. Há objetivos e finalidades que fazem com que a prática educativa transborde dela mesma.

De fato, não há como desvincular a formação do professor dos aspectos atinentes a exigências atuais e à complexidade que envolve questões contemporâneas marcadas pelas mudanças sociais, econômicas, políticas, tecnológicas, especificamente no campo da comunicação, provocando o aumento exponencial do acesso ao conhecimento e a sua mercantilização, que acentuam o aligeiramento e a banalização da informação, geram crises nos diversas esferas da sociedade, reverberando diretamente nos diferentes níveis de formação pessoal, profissional e nos desafia a buscar, a construir outras configurações teórico-metodológicas que contribuam para o entendimento das especificidades da formação para a docência. 
Nesse sentido, o eixo estruturante do presente estudo é a discussão e a reflexão sobre o uso da escrita autobiográfica enquanto instrumento na formação inicial de professores. Trata-se de um relato de experiências com apontamentos sobre as vivências nas aulas de Didática Geral oferecidas nos cursos de licenciatura da Universidade Federal de Uberlândia (UFU) desde 2011. Essas experiências suscitam inquietações e recorrentes questionamentos: Como instigar o interesse dos estudantes em relação à docência? Por que os licenciandos, em geral, não assumem a docência como profissão? Por que eles não compreendem que a profissão docente requer um campo epistemológico específico como base da formação?

Ao iniciarmos os semestres, nos primeiros contatos com os estudantes, perguntamos sobre os "porquês" da escolha por cursos que formam professores. As respostas são, em geral, similares aos dados apresentados em diversas pesquisas realizadas no Brasil e no exterior sobre a escolha da profissão docente na educação básica: desânimo advindo de sucessivas tentativas de ingresso em outro curso de graduação (exemplo: o aluno opta por licenciatura em Matemática, após fracassar no vestibular para Engenharia); não sabiam o que escolher; opção de cursar ao mesmo tempo bacharelado e licenciatura (sendo a licenciatura considerada como apêndice do bacharelado); outros afirmaram o desejo de exercer a docência, porém não na educação básica - essa escolha decorre, segundo eles, da desvalorização social e econômica da profissão. Desse desinteresse decorrem as constantes reclamações quanto aos objetivos do curso de licenciatura e em específico das disciplinas "pedagógicas". Em geral, os alunos não se empenham nas leituras e nas atividades propostas; esperam da Didática, receitas prontas de como ensinar.

A busca por estratégias metodológicas que favoreçam "inéditos viáveis" na formação de professores em cursos de licenciatura para o exercício da docência na educação básica tem sido desafio permanente no desenvolvimento da disciplina Didática Geral e a partir da análise das dificuldades no processo ensino-aprendizagem, discutimos as possibilidades de superar, como explica Freire (2011), as "situações-limite", em que licenciandos compreendem as dificuldades interpostas na prática pedagógica e na vida pessoal dos professores. Mediante a realização de "atos limites" (ações de resistência e ousadia), alcançam-se "inéditos viáveis" ou "soluções praticáveis despercebidas" que podem promover a análise crítica da realidade e a (trans)formação individual e coletiva, fomentando condições voltadas à práxis para agir e modificar o mundo.

As observações e análises advindas das atividades em sala de aula indicam que a assunção da profissão docente, por parte dos licenciandos, pode ser alcançada em um movimento que contemple a reflexão sobre a vida deles. Aprender com a própria experiência e autoquestionar sobre as próprias escolhas constitui a nossa proposta a eles, pois acreditamos que esse é "[...] um processo profundamente emancipado em que o sujeito aprende a produzir sua própria formação, autodeterminando sua trajetória" (CUNHA, 1998, p. 40). 
A esse respeito, Nóvoa (1992a, p. 26-27) considera que os cursos de formação docente necessitam promover condições para que os futuros profissionais se assumam como "produtores de sua própria profissão"; logo, trabalhar na perspectiva da autobiografia é recuperar a dimensão de que "[...] o professor é a pessoa e parte importante da pessoa é o professor".

Constatamos que o desenvolvimento dessa experiência possibilita ampliar as nossas reflexões sobre os dilemas e desafios enfrentados no território da formação inicial de professores. Isso ocorre, sobretudo, no que concerne à inclusão de práticas de ensino alternativas que promovam um olhar mais apurado sobre as interfaces das histórias de vida - percursos pessoal e profissional - dos sujeitos em formação e suas implicações na construção da identidade profissional docente.

As reflexões oriundas do referencial teórico-metodológico adotado-Benjamin (1994), Bosi (1983), Campos e Silva (2015), Cunha (1990), Delory-Momberger (2004), Dominicé (2000), Freire (1991, 1996, 2000, 2011), Fonseca (1997; 2006), Josso (2005), Marcelo Garcia (1999), Nóvoa (1992 a; 1992 b), Nóvoa e Finger (1988), Rios (2002), Pimenta (1999), entre outros - contribuíram significativamente para compreender o processo de formação a partir de interrogações sobre a imagem constituída sobre a docência, em se tratando do discente em formação inicial e possibilitou-nos elaborar um instrumento, o qual nomeamos "Projeto (trans)formação para a docência: o discente como sujeito de sua (trans)formação", com o qual temos desafiado os discentes a se posicionarem frente a escolha pela profissão docente.

\section{ESCRITAS REFLEXIVAS SOBRE SI}

Não seremos de todo infelizes se pudermos contar a nós mesmos a nossa história. Se nos for garantido o direito ao conhecimento de nós mesmos como profissionais (ARROYO, 2013).

Ao contarmos a nossa história, não abordamos somente a nossa vida, formação escolar na condição de estudante ou de professores, e sim uma narrativa que está atravessada por outras - família, comunidade, amigos, condições sociais, políticas e culturais. Diante disso, torna-se necessário constituir espaços e tempos na formação de professores, para acolher e colocar em movimento (crítico, reflexivo e formativo) manifestações de subjetividade, para que os discentes expressem suas crenças e valores. Nesse caso, Larrossa (2004, p. 12-13) enfatiza que o ser humano interpreta e, "[...] para essa autointerpretação, utiliza fundamentalmente formas narrativas. [...] o sentido de quem somos, tanto para nós mesmo como para os outros, depende das histórias que contamos e que nos contamos".

A narrativa da própria vida, nas palavras de Bosi (1983), é o testemunho mais eloquente dos modos que a pessoa tem de lembrar. É a sua memória compreendida não como sonho, e sim como trabalho. Lembrar não é reviver; lembrar é refazer o percurso, repensar e reconstruir, com imagens e ideias de hoje, as experiências do passado. Ao 
recordarmos, refletimos sobre como compreendemos nossa própria história e a dos que nos cercam.

Inscrevemo-nos cotidianamente na história que não está mais distante, e sim impregnada das memórias que nos tomam e da qual outros indivíduos fazem parte. Com a narrativa de nossas experiências, aprendemos que os acontecimentos passados assumem vários matizes - refletimos, nos dobramos sobre a própria vida e apreendemos conceitos que são "as senhas com que se de-senha a realidade" (NICOL, 1997, p.352).

De acordo com Josso (2005), o recurso biográfico no devir formativo permite o exercício do "autoformar-se". A autora analisa a abordagem biográfica como metodologia de pesquisa-formação e discute sobre o poder transformador das narrativas, à luz dos diferentes papéis desempenhados na sua construção e interpretação.

Afirma-se que a pesquisa sobre a "formação de si" implica necessariamente em questionamentos para aprendermos a aceitar os desafios postos pelas histórias de vida. Ter acesso ao modo como cada pessoa se forma é abarcar singularidade da própria história e a complexidade da profissão docente, pois, segundo Ferrarotti (1998, p. 26-27):

O homem é o universal singular. Pela sua práxis sintética, singularizada nos seus actos a universalidade de uma estrutura social. Pela sua atividade destotalizadora/retotalizadora, individualiza a generalidade de uma história social colectiva. Eis-nos no âmago do paradoxo epistemológico que nos propõe o método biográfico. [...] Se nós somos, se todo o indivíduo é a reapropriação singular do universal social e histórico que o rodeia, podemos conhecer o social a partir da especificidade irredutível de uma práxis individual.

Essa concepção nos levou a formular a hipótese de que, se os estudantes escrevessem suas histórias de vida, poderiam retomar, na singularidade do aprendido, a complexidade da profissão docente e, em um movimento de expansão, o processo formativo complementaria as lacunas, preencheria os não ditos, instigaria a busca de novas respostas, explicaria suas ações e opções, pois "[...] a escrita da narrativa remete o sujeito para uma dimensão de autoescuta de si mesmo, como se tivesse contado para si próprio suas experiências e as aprendizagens que construiu ao longo da vida por meio do conhecimento de si" (SOUZA, 2005, p.53).

Nesses termos, consideramos que os discentes, ao escreverem o Projeto de (trans)formação para a docência, têm a possibilidade de recuperar, na trajetória escolar, concepções pedagógicas, conteúdos, valores, marcas que implícita e explicitamente influenciam e/ou influenciarão a prática docente.

Desde 2011 propomos aos estudantes, no início de cada semestre letivo, a elaboração do Projeto de Formação para a Docência enquanto instrumento reflexivo, cujo objetivo é a 
assunção da identidade e da profissão docente ${ }^{3}$. Para instigá-los a se lembrarem do percurso formativo, apresentamos, em rodas de conversa ${ }^{4}$, alguns questionamentos que incitam a reflexão inicial: $\mathrm{O}$ que move você para se tornar professor, professora? O angustia você na escolha pela profissão docente? O que você considera importante aprender para exercer a profissão docente? O que você espera realizar como professor, como professora?

Nas rodas de conversa, o diálogo é um momento singular de partilha, pois pressupõe um exercício de escuta e fala, em que se agregam vários interlocutores - nesse sentido, os momentos de escuta são mais numerosos que os de fala. As experiências de vida traduzem a percepção do discente, mas ele não narra sozinho: reproduz vozes, discursos e memórias de outras pessoas que se associam à sua no processo de rememoração e de socialização. 0 discurso narrativo, no caso da roda de conversa, é uma construção coletiva:

O diálogo não é uma situação na qual podemos fazer tudo o que queremos. Isto é, ele tem limites e contradições que condicionam o que podemos fazer. Para alcançar os objetivos de transformação, o diálogo implica em responsabilidade, direcionamento, determinação, disciplina, objetivos (FREIRE; SHOR, 1987, p. 127).

A partir das reflexões coletivas, entregamos um roteiro aos licenciandos com orientações gerais para a preparação do Projeto de (trans)formação para a docência, que deve ser organizado em três partes. Na introdução há as impressões deles segundo suas lembranças, recuperando as pessoas que influenciaram sua aprendizagem - pais, familiares, professores etc. Já na segunda seção, eles se posicionam sobre a fundamentação teórica indicada e discutida na disciplina. E na terceira etapa os estudantes refletem criticamente sobre os seguintes pontos: a) limites e possibilidades de ser professor; b) perspectivas de atuação profissional após a elaboração do Projeto de Docência; c) contribuições da disciplina Didática Geral para o exercício da docência na área de formação.

Após apresentarmos aos alunos a proposta do Projeto de (trans)formação para a docência, identificamos que há, em geral, certa resistência oriunda do medo da exposição e

\footnotetext{
${ }^{3}$ Há sete anos (2011-2018) propomos aos estudantes, no início de cada semestre letivo, disciplina Didática Geral oferecida nos cursos de licenciatura da UFU a elaboração do Projeto de Formação para a Docência enquanto instrumento reflexivo, cujo objetivo é a assunção da identidade e da profissão docente. Ao final de cada semestre reavaliamos o instrumento, a partir da produção dos estudantes. A partir de 2016 passamos a organizar o conjunto de textos produzidos pelos estudantes com auxílio do software NVivo para otimizar a composição do corpus de analise em função da extensão do material obtido. Para compor o corpus de análise no software, as temáticas foram analisadas por meio de seus respectivos recortes discursivos objetivando apreender nos relatos suas experiencias em relação a cada temática, mas também procurando, nas analises, 0 entrecruzamento das narrativas o há de singular, diverso, contraditório. Embora consideremos que os recursos disponíveis no software não substituam a leitura e a reflexão, eles contribuem para que as análises sejam mais completas e confiáveis. Informações sobre o Nvivo podem ser obtidas em:

https://www.qsrinternational.com/nvivo/home

${ }^{4}$ A roda de conversa é uma estratégia simples: reunidos em círculo, os alunos expressam pontos de vista segundo questões apresentadas pela professora. A participação coletiva no debate sobre determinada temática, a partir do diálogo no qual os discentes se posicionam e escutam seus pares e a si mesmos por meio do exercício reflexivo.
} 
da consequente avaliação. É comum aos discentes afirmarem que se lembrar de todos os aspectos relacionados às suas vidas e responderem aos questionamentos propostos é uma tarefa impossível. Outros contestam a proposta por considerarem bastante subjetiva, questionando a pertinência da memória individual como contributo ao processo de formação.

Não obstante as resistências e reclamações, a maior parte dos estudantes, ao recuperarem determinadas passagens de suas histórias e com vários personagens, reavaliaram as experiências escolares, se surpreenderam com os acontecimentos vivenciados, ficaram entusiasmados e reconheceram o quão significativo foi o mergulho nessas narrativas. Compreender, de acordo com Puig (1998, p. 35), "[...] supõe, antes de tudo, perguntar-se algo e abrir com isso um espaço de novas significações e sentidos".

Após alguns anos com a proposta desse trabalho a diferentes turmas dos cursos de licenciatura, notamos um acolhimento significativo: os mais jovens anseiam por contarem suas histórias e até ilustrá-las com fotos, alguns mais experientes se sentem sensibilizados ao falarem sobre suas vidas, mas a maioria se dedica à tarefa com satisfação e esmero, pois, ao entrarem em contato com o referencial teórico, redimensionam as concepções sobre a memória enquanto mero produto de uma atividade meramente subjetiva.

Com base nas proposições de Halbwachs (1956), depreendemos que as lembranças são consequência da "reconstrução do vivido", e delas podem ser desencadeadas análises e reflexões significativas, pois, para compreender o presente, é preciso pesquisar sobre o percurso vivido, identificar, analisar e conhecer as interações. Segundo o autor, a memória revela e acompanha as opções pelas mudanças ou a resistência a elas; representa uma arte não só do que aconteceu, como também do que deixou de acontecer, bem como aquilo que poderia ou deveria ter ocorrido.

Constatamos nos relatos dos licenciandos que, uma vez superadas as dificuldades iniciais para produzir a narrativa, o mergulho em busca de si é inevitável. A ação de "escrever sobre si" desafia os alunos a (re)contar o vivido e a questionar o sentido de "ser humano", sobretudo no que tange à formação para a docência e ao valor por eles atribuído à profissão docente e à vida deles. Nesse entremeio, tornar-se professor, professora passa a ser uma construção singular que toma forma na conjuntura da própria existência, visto que a ação de ensinar suscita uma aprendizagem permanente e contínua, marcada pela descontinuidade que implicará na compreensão e assunção da passagem de estudante para docente. Nóvoa (1992b) também assinala tal relevância, ao dizer que os cursos de formação deveriam possibilitar, aos estudantes, a percepção como autores da própria vida.

O Projeto de (trans)formação para a docência é um gênero textual predominantemente narrativo, circunstanciado e analítico, que trata do processo de formação num determinado período. O passado lembrado não é linear. A narração avança e 
recua sobre a linha do tempo, como que transbordando a finitude espaço-temporal que é própria dos acontecimentos vividos (BENJAMIN, 1987).

A palavra "narrar" vem do verbo latino narrare, que significa "expor", "contar", "relatar", e se aproxima do que os gregos antigos chamavam de épikos - poema longo que conta uma história e serve para ser recitado. Narrar tem uma característica intrínseca: pressupõe o outro. Por conseguinte, a narrativa de formação oferece um terreno de implicação e compreensão sobre como conceber o passado, o presente e, de forma singular, as dimensões experienciais da memória de escolarização. Para Souza (2006, p. 59), a “[...] escrita da narrativa da trajetória de escolarização permite ao sujeito compreender, em medidas e formas diferentes, o processo formativo e os conhecimentos que estão implicados nas suas experiências ao longo da vida".

De fato, as narrativas são instrumentos efetivos de recriação da realidade social que possibilitam às pessoas terem não apenas um lugar na história, como também um papel importante na produção do conhecimento. A realidade cotidiana é percebida por nós de um modo particular, em que damos sentido às situações por meio do nosso universo de crenças, elaborado a partir de vivências, valores e papéis culturais inerentes ao grupo social a que pertencemos.

Para produzir a "escrita de si", devemos conhecer as condições em que estão circunscritas as lembranças, assim como os acontecimentos e personagens que predominaram segundo as escolhas feitas. Nesse sentido, o Projeto de (trans)formação para a docência não é apenas uma crítica que forçosamente avalia ações, ideias, impressões e conhecimentos dos narradores, é também autocrítico da ação daqueles que expõem, seja como autores do texto ou como sujeitos da lembrança, e se relaciona com as condições, situações e contingências que envolveram a ação dos narradores protagonistas das memórias. Além de ser (auto)crítico, é um pouco confessional, apresentando paixões, emoções, sentimentos inscritos na memória.

A narrativa de vida, como pontua Josso (2005), não tem em si um poder transformador; contudo, a metodologia de trabalho sobre essa narrativa pode indicar uma transformação, segundo a natureza das tomadas de consciência realizadas nesse contexto e o grau de abertura à experiência dos sujeitos envolvidos no processo. Nesse caso, as narrativas não dizem respeito, necessariamente, à totalidade da vida das pessoas, e sim aos aspectos dessa vivência, os quais constituem informações para a reconstituição de fatos e problemáticas. Na interpretação e análise das narrativas se refletem as condições construídas historicamente por esses sujeitos, com variações limitadas. Estas, por sua vez, permitem identificar diferentes pontos de vista parciais, contradições e tensões, leituras e interpretações diversas em um processo de construção permanente. 
Catani et al. (1997) entendem que o trabalho com a história de vida, memória e autobiografia tem contribuído na pesquisa educacional e na elaboração de uma "contramemória", com a produção de relatos autobiográficos. Estes possibilitam desconstruir imagens e representações sobre a prática docente, fundamentos teóricos da prática; logo, se contrapõe à memória oficial disseminada pelas políticas de formação e pela literatura pedagógica que vem estruturando o trabalho docente.

O Projeto de (trans)formação para a docência, no contexto da disciplina Didática Geral, se converteu em um recurso valioso para a análise da prática pedagógica. Nele, os alunos fizeram uso de narrativa, foram incentivados a escrever e a refletir sobre o percurso escolar e a trajetória de vida, salientando o caráter histórico. Tais sujeitos compreenderam o papel de protagonistas que representam na História e se sentiram instigados a buscar diversificadas influências que, de alguma forma, os levaram a escolher a docência como profissão. Ao escreverem sobre suas histórias e relembrarem as condições escolares vivenciadas, além de reverem a própria prática como estudantes ou professores, identificam o próprio processo de aprendizagem.

\section{A FORMAÇÃO DOCENTE (COM)PARTILHADA}

Somos o lugar onde nos fizemos, as pessoas com quem convivemos. Somos a história de que participamos. A memória coletiva que carregamos [...] ser professor faz parte de nossa vida pessoal. É um outro em nós (ARROYO, 2007).

Compartilhar fragmentos ${ }^{5}$ das histórias contadas por futuros professores diz respeito à possibilidade de ouvir do outro o que está, muitas vezes, silenciado em nós. Ser contada ou ser lida: este é o destino de toda história.

Na leitura dos Projetos de (trans)formação para a docência entendemos, a partir do conceito de experiência formadora, o que cada um dos graduandos elegeu como atividade significativa de suas vidas. Às vezes, paradoxalmente entre o passado e o futuro, surgiram questionamentos contextuais vividos no presente, como podemos perceber nos fragmentos a seguir:

\footnotetext{
${ }^{5} \mathrm{O}$ uso de excertos das narrativas discentes, organizadas nos Projetos de Formação para a Docência, foi autorizado pelos autores dos textos. Vale ressaltar que os nomes não foram revelados para resguardar a identidade dos estudantes, considerando o curso em que eles se graduaram e o respectivo ano em que cursaram a disciplina Didática Geral.
} 
Relatar minha trajetória pessoal e profissional se trata, antes de tudo, de um grande desafio. Em primeiro lugar, porque as reminiscências são sempre diferentes umas das outras, ainda que sejam sobre de um mesmo momento da vivência. Depois porque o esquecimento parece ser algo inerente à condição humana. Penso que tanto o "lembrar" quanto o "esquecer" recheiam as experiências de homens e mulheres, independendo de espaços e tempos (LICENCIATURA EM HISTÓRIA, 2011).

Ao escrever o meu Projeto de (trans)formação para a docência, recuperei muitas lembranças adormecidas; lembrei-me das pessoas que contribuíram para minha constituição do ser professor, dos muitos ensinos que tive durante toda minha vida. Pude refletir mais sobre o papel do professor e perceber o quanto influenciamos nossos alunos com nossas atitudes e valores que defendemos (LICENCIATURA EM GEOGRAFIA, 2017).

Geralmente, o Projeto de (trans)formação para a docência tem desafiado os licenciandos a se posicionarem frente à escolha pela docência:

Eu ainda continuo não querendo ser professor, mesmo depois de escrever sobre eles. Acho que não tenho essa vocação. A gente tem que fazer o que gosta. Pode ser que eu mude de opinião. Escrever esse Projeto de (trans)formação para a docência me mostrou a importância dos professores na minha vida. Não falo só dos "tios" da escola. Foram meus pais, avós, amigos e tantas pessoas que já nem me lembro dos nomes ou dos rostos, mas que me marcaram muito e contribuíram para que eu fosse o que eu sou hoje (LICENCIATURA EM ENFERMAGEM, 2015).

Para aqueles que já têm uma posição definida, com relação ao fato de ser professores, o trabalho foi fundamental aos que precisavam se perguntar sobre as razões de estar cursando a licenciatura e o que fariam quando se tornassem egressos do curso:

Não me recordo qual foi o momento exato da vida que escolhi ser professora. Tive uma infância repleta de brincadeiras, amigos e liberdade. Nesse tempo, que não faz tanto tempo assim, há uns 20 poucos anos, brincávamos na rua livremente. Brincávamos de tudo, mas a minha brincadeira preferida era de escola. Minhas amigas brincavam representando médicas, modelos, advogadas, psicólogas, artistas e eu..., a professora. Agora que estou quase terminando o curso, me pergunto se ser professora é realmente o que eu quero (LICENCIATURA EM MATEMÁTICA, 2014).

Escrevo primeiramente sobre minha formação, minhas memórias, meus anseios, frustrações, aprendizados e reflexões. Desde criança queria ser professora. Acho que foi influência de minha avó, de minha mãe e das tias. Quando prestei vestibular para Letras, ninguém entendeu [...] fiquei frustrada porque pensei que todo mundo sabia que eu seria professora. Só não sei ainda como será porque a escola está muito complicada (LICENCIATURA EM LETRAS, 2017).

Eu não queria ser professor, mas a opção de entrar na universidade, em um curso pouco concorrido foi a minha escolha na época. Hoje penso de outra maneira: ser professor exige comprometimento comigo e com os outros. É muita responsabilidade e acho que ainda não estou preparado. Tenho que aprender muito ainda (LICENCIATURA EM FÍSICA, 2016).

Historicamente, a profissão docente tem sido alvo de muitas críticas, cobranças e acusações advindas de setores sociais diversos, o que gera certo clima de insatisfação e desconforto em relação à escolha profissional pela docência. A imagem social do professor é uma construção social atravessada por inúmeras concepções formuladas a partir de relações 
sociais, políticas e culturais que, imbricadas, desencadeiam representações que os docentes fazem de si mesmos, de suas funções e dos discursos que circulam no mundo.

As condições objetivas de trabalho e a desvalorização social da profissão de professor são alguns pontos que interferem diretamente na construção da identidade de futuros professores, uma vez que a identificação com o magistério diz respeito ao significado pessoal e social que a profissão tem para a pessoa, ou seja, se o professor perde o significado do seu trabalho, tanto para si quanto para a sociedade, ele perde a identidade com a sua profissão. A esse respeito, Pimenta (1999, p. 19) assevera que:

A identidade profissional se constrói, pois, a partir da significação social da profissão, da revisão constante dos significados sociais da profissão; da revisão das tradições. [...] constrói-se também pelo significado que cada professor, enquanto ator e autor, confere 'a atividade docente no seu cotidiano a partir de seus valores; de seu modo de situar-se no mundo, de sua história de vida, de suas representações, de seus saberes, de suas angústias e anseios, do sentido que tem em sua vida o ser professor.

As narrativas de vida, de acordo com Josso (2005), constituem um importante instrumento de investigação para entender a construção da identidade. Isso favorece a reflexão sobre as expressões identitárias, evidenciando a pluralidade, a fragilidade e as recomposições possíveis. Nos diálogos com os estudantes sobre as imagens construídas no cotidiano escolar contribuem para compreendermos que os professores não se constituem por uma única identidade, mas sim por várias, uma vez que são sujeitos plurais, múltiplos, resultantes da união de imagens individuais e coletivas. De acordo com Arroyo (2007, p. 29), há inúmeras possibilidades de sermos professores, pois:

Somos a imagem que fazem de nosso papel social, não o que teimamos ser. Teríamos de conseguir que os outros acreditem no que somos. Um processo social complicado, lento, de desencontros entre o que somos para nós e o que somos para fora. Entre imagens e autoimagens.

Sob esse viés, o Projeto de (trans)formação para a docência tem permitido aos discentes desmistificarem certos tabus e crenças construídos ao longo de suas vidas, a respeito do que é ser "bom" ou "mau" professor. Muitos alunos relataram situações de constrangimento, angústia, decepção, frustração, entre outros sentimentos negativos ligados a lembranças de sala de aula. Entretanto, ao analisarem esses enfrentamentos, alguns indicaram aspectos para superar os equívocos dos antigos professores, conforme os projetos voltados ao futuro exercício na profissão:

O Projeto de Formação para a Docência me fez refletir sobre as atitudes dos meus professores. Erros e acertos foram constantes e inevitáveis. Levarei essas reflexões para a minha vida de educador, buscando despertar em meus alunos tantas coisas bonitas que a lembrança dos meus professores despertou em mim (LICENCIATURA EM ARTES VISUAIS, 2016).

Além da percepção do professor como elemento humano, os alunos definiram o espaço escolar como um lugar de relações e emoções: 
Acredito que esses anos passados na escola mexem profundamente com nossa experiência de vida. Nesse momento, a escola nos educa muito mais do que a família, e não é simplesmente a educação formal. O convívio, muitas vezes doloroso, com os nossos colegas nos ensina muito. Nos intervalos e mesmo na sala, convivemos com preconceitos de ordem estética, racial e de classe. Sobreviver a isso não é fácil. Porém, isso nos prepara para a vida (LICENCIATURA EM FILOSOFIA, 2015).

$\mathrm{Na}$ análise das relações entre professores e alunos, nos diversos espaços-tempos vividos, identificamos não só como aprendemos ou ensinamos, mas também como nos formamos para ensinar, o que influencia no entendimento sobre essas relações no contexto atual. Os espaços-tempos educativos existentes na escola e para além dela são, segundo Alves (2006, p. 26):

[...] o locus do que se denomina docência coletiva, no qual somos, todos e todas, discentes - docentes [...] admitindo que em todos os espaços-tempos educativos se dão trocas diversas e múltiplas, nas quais aprendemos e ensinamos, todos a todos, o tempo todo.

Os espaços-tempos escolares estão repletos de relações e mediações que remetem às pessoas que por eles transitaram (e ainda transitam) e neles inscreveram (e continuam a inscrever) a história de suas vidas. Nas (entre)linhas das narrativas dos licenciandos foi possível, como preconiza Orlandi (1994, p. 59):

[...] colocar o dito em relação ao não dito, o que o sujeito diz em um lugar com o que é dito em outro lugar, o que é dito de um modo com o que é dito de outro, procurando ouvir, naquilo que o sujeito diz, aquilo que ele não diz, mas que constitui igualmente os sentidos de suas palavras.

A análise dos relatos nos permitiu compreender que cada profissional se constitui em diferentes espaços e tempos, pois compomos um emaranhado de tramas, redes e espaços dos quais participaram (e participam) muitos professores e outros "eus" que, numa tessitura de fios, texturas e cores variadas nos tornaram em parte aquilo que somos, tal como poeticamente Álvaro de Campos escreveu: "Sim, sou eu, eu mesmo, tal qual resultei de tudo... Quanto fui, quanto não fui, tudo isso sou... Quanto quis, quanto não quis, tudo isso me forma" (CAMPOS, 1993, p. 114).

Isso implica que, para compreendermos a natureza da constituição da profissão docente, é necessário considerarmos a subjetividade que nos constitui e, de acordo com Arroyo (2007, p.34), o modo como os professores assumem suas práticas se dá conforme o significado que atribuem à profissão:

No convívio com professoras e professores percebo que há um a preocupação por qualificar-se, por dominar saberes, métodos, por adequar sua função social aos novos tempos, novos conhecimentos e novas tecnologias. Porém não é por aí que se esgotam as inquietações. Há algo mais fundo em questão: o próprio sentido social de suas vidas, se seus esforços, de sua condição de mestres. Entender o papel que exercem, o peso social e cultural que carregam. Sua condição. Seu ofício. Seu ser professor, professora. 
Nesse sentido, compreendemos o Projeto de (trans)formação para a docência como um caminho investigativo da constituição da subjetividade docente. Ao analisar os relatos dos licenciandos, pudemos apreender o entrelaçamento de vários contextos formativos ou espaços estruturais de formação, assim como identificamos a oportunidade ímpar (e, porque não, par) de haver mudanças.

Ao recuperarmos o conceito de docência tanto no espaço sensível quanto no intelectual, notamos que ele é um ponto importante a ser agregado na formação discente, se entendermos que o ato educativo se reveste de uma gama de emoções, sentimentos e afetos que não pode ser ignorada. Convém salientar que a pesquisa e a reflexão não excluem o papel dessa dimensão humana que também é técnica, política, estética e ética (RIOS, 2001).

Os Projetos de (trans)formação para a docência, como instrumentos de pesquisa na constituição dessa área, desencadeiam a reflexão discente não só sobre si mesmo, como também sobre os indivíduos envolvidos no entorno educacional onde estão inseridos. Essa percepção nos permite ampliar a compreensão de que aprender "[...] não é apenas aprender isto ou aquilo; é descobrir novos meios de pensar e de fazer diferente; é partir à procura do que poderá ser este diferente" (JOSSO, 2005, p. 241).

O "fazer diferente" do aprendido é o desejo de muitos alunos, uma responsabilidade atribuída à Didática Geral:

\begin{abstract}
E é justamente aí que reside o meu interesse: a Didática consegue desvelar, com certa segurança, um pouco da realidade que está por vir. Sem sobressaltos, consigo perceber que a minha formação em História passou a ter mais "substância", os meus objetivos não ficam mais presos somente à própria História, mas ao meu processo educativo de forma geral (LICENCIATURA EM HISTÓRIA, 2017).

Acredito que poderei ser um professor melhor. Agora compreendo o quanto é difícil mudar, fazer diferente dos meus professores. Eu pensava que não era importante essa "coisa" da pedagogia. Ensinar exige muito do professor, mas sem o compromisso e sem a formação (acho que é para o resto da minha vida) não conseguirei uma prática, uma didática que possibilite a aprendizagem dos meus alunos (LICENCIATURA EM MATEMÁTICA, 2015).
\end{abstract}

As narrativas registradas nos Projetos de (trans)formação para a docência se revelaram imprescindíveis para os futuros docentes. Elas favorecem reflexões sobre as experiências formadoras, promovem aprofundamentos sobre o conhecimento de si e ampliam os significados da prática didático-pedagógica vivenciada em experiências individuais com os professores desses indivíduos.

Quanto à identificação com os professores na educação básica e na graduação, os estudantes reclamam que eles, apesar de dominarem o conteúdo específico da disciplina, não sabem como transmiti-lo: afirmam que os docentes não sabem conduzir a aula, não se importam com o aluno, são distantes (e, por vezes, arrogantes) ou não se preocupam com a docência, priorizando trabalhos de pesquisa, e não fundamentam a formação para a docência 
além do espaço de sala de aula e dos muros da instituição. Esse descontentamento provoca a evasão, principalmente no primeiro e segundo ano dos cursos de graduação.

Embora desejem realizar ações diferentes de seus professores, a docência, na perspectiva dos licenciandos, ainda se circunscreve ao exercício da docência na educação básica e indica, de forma geral, que "dar aulas" é uma ação restrita ao espaço da sala de aula. Foi possível também identificar que os estudantes consideram que a formação específica para a profissão docente ainda é algo supérfluo, ou mesmo desnecessário, e raramente identificam a imprescindibilidade dessa formação.

Representações discentes sobre a docência ainda estão cristalizadas em um ideário difícil de ser superado: a compreensão do magistério como vocação ou dom, a imagem de perfeição dos professores como sujeitos que tudo sabem; consequentemente, "quem sabe, ensina". Embora esse constructo conservador seja recorrente nas expressões discentes, depreendemos que a prática alternativa de pensar, ensinar e aprender a docência, por meio do recurso autobiográfico, configura a importância desse instrumento como eixo organizador do trabalho na produção de conhecimentos no âmbito das licenciaturas, superando concepções e práticas adjetivadas como tradicionais que ainda estão presentes nos cursos de formação de professores. Uma forma de conduzir esse processo é eleger as crenças do professor como objeto de reflexão (GARCIA, 1999).

É necessário, por conseguinte, formar docentes que repensem a própria prática, na condição de estudantes em formação, em se tratando do exercício específico requerido pela profissão, na expectativa de que a reflexão seja um instrumento para desenvolver, para (trans)formar o pensamento e a ação.

Ademais, avaliamos que o Projeto de (trans)formação para a docência tem possibilitado aos estudantes a reflexão a respeito da dimensão humana do ato educativo, dos dilemas, dos desafios subjacentes à prática educativa e das mudanças no processo formativo que se amalgamam à identidade docente, pois "[...] as histórias não se desprendem apenas do narrador, narrar é resistir. É por em ordem o existir" (ROSA, 1985, p. 98).

\section{ESCRITA DE SI: POSSIBILIDADES DE (TRANS)FORMAÇÃO PARA A DOCÊNCIA}

O Projeto de (trans)formação para a docência foi concebido e tem sido vivenciado como uma possibilidade de reflexão sobre os processos formativos. O sujeito em formação compartilha experiências e práticas ao se utilizar de um referencial teórico que promove análises e reflexões sobre a constituição da sua identidade docente.

Ao elaborarem o (trans)formação para a docência, os licenciandos reconhecem que caminhar para si significa olhar para a própria vida. Muitos, inclusive, conseguem enfrentar seus medos, aceitam os momentos difíceis como aprendizado, celebram os bons momentos, descobrem que o sentido do aprendizado está no próprio viver e compreendem a dimensão humana em um processo permanente de formação e desenvolvimento da docência.

(C) ETD-Educação Temática Digital Campinas, SP $\quad$ v.21 $\quad$ n.1 $\quad$ p.242-258 jan./mar. 2019 
Ainda que a proposta de elaboração do (trans)formação para a docência seja comum às diferentes turmas e que o seu desenvolvimento aconteça em semestres diferentes, as produções têm se apresentado de maneira particular, revelando singularidades e relatos múltiplos e diferenciados. Diferem também sobre como os estudantes tecem, tramam e enredam suas lembranças.

A partir do conjunto de mais de 400 Projetos de (trans)formação para a docência - um vasto acervo e uma imensa fonte de dados, podemos afirmar que, quando os discentes organizam os fragmentos de suas histórias de vida, é como se costurassem colchas de retalhos, nas quais os pedaços de tecidos, com tramas e texturas diversas, são unidos pelo fio da memória. A singularidade expressa nas narrativas, evidencia "coisas de rasa importância no contar seguido, alinhavado", como nos ensina Rosa (1986), das vivencias de cada estudante. Esse trabalho é único e artesanal; nele os alunos, autores de suas histórias, imprimem suas marcas indeléveis e (trans)formam para a docência (CAMPOS, 2010).

Por esse viés, o Projeto de (trans)formação para a docência adquire um valor social e afetivo para os seus autores e para nós também, pois, no movimento das discussões, problematizações e reflexões, nos constituímos profissionalmente - professoras formadoras e futuros professores -, olhamos para nós mesmos, com nossas crenças e práticas, e vivenciamos a produção das próprias identidades e subjetividades. A construção da identidade docente, como explica Nóvoa (1992b, p. 16), “[...] não é um dado adquirido, não é uma propriedade, não é um produto. A identidade é um lugar de lutas e de conflitos, é um espaço de construção de maneiras de ser e de estar na profissão".

Destarte, as análises e reflexões dos Projetos de (trans)formação para a docência nos permitem reiterar que no processo de escrita de si há um movimento contínuo de (trans)formação para compreender, conforme a visão dos próprios licenciandos, o universo da formação profissional para o exercício da docência. Na dialética entre o "coletivo" e o "individual" se instaura, porquanto, a margem criadora da subjetividade social e histórica (com)partilhada no processo (trans)formativo.

\section{REFERÊNCIAS}

ALVES, N. As redes de conhecimentos e as relações professoras-alunos/alunas: sobre a ideia de "docente coletivo" ou os "docentes-discentes". In: COLÓQUIO LUSO-BRASILEIRO SOBRE QUESTÕES CURRICULARES, 3., 2006, Braga. Anais... Braga: Universidade do Minho, 2006.

ARROYO, M. G. Ofício de mestre: imagens e autoimagens. Petrópolis: Vozes, 2007.

ARROYO, M. G. Currículo, território em disputa. Petrópolis: Vozes, 2013.

BENJAMIN, W. Experiência e pobreza. In: BENJAMIN, W. Magia e técnica, arte e política: ensaios sobre literatura e história cultural. São Paulo: Brasiliense, 1994.

BENJAMIN, W. O narrador - considerações sobre a obra de Nikolai Leskov. In: BENJAMIN, W. Magia e técnica, arte e política: ensaios sobre literatura e a história da cultura. São Paulo: Brasiliense, 1987, p. 197-221. (Obras Escolhidas, v. 1).

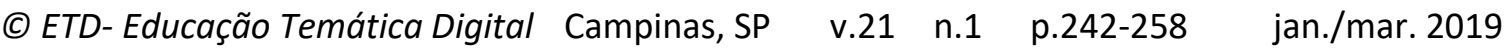


BOSI, E. Memória e sociedade: lembrança de velhos. São Paulo: TA Queiróz/EDUSP, 1983.

CAMPOS, Á. de. Sou eu. In: PESSOA, F. Poesias de Álvaro de Campos. Fernando Pessoa, 1944. Lisboa: Ática, 1993.

CAMPOS, V. T. B.; SILVA, F. D. Projeto de formação para a docência: contribuições à constituição da identidade docente. In: QUILLICI, A.; SILVA, F.; SOUZA, V. (Org.). Formação de professores: perspectivas e contradições. Uberlândia: Composer, 2015.

CAMPOS, V. T. B. Marcas indeléveis da docência no ensino superior: representações relativas a docência no ensino superior de pós-graduandos de instituições federais de ensino superior. 2010. Tese (Doutorado em Educação) - Faculdade de Educação, Universidade de São Paulo, São Paulo, 2010. Disponível em: http://www.teses.usp.br/teses/disponiveis/48/48134/tde-14062010-123952/pt-br.php . Acesso em: 20 janeiro 2017.

CATANI, D. B.; BUENO, B. O. SOUZA, M. C. C. C.; SOUSA, C. P. de (Org.). Docência, memória e gênero: estudos sobre formação. São Paulo: Escrituras, 1997.

CUNHA, M. I. da. O professor universitário na transição de paradigmas. Araraquara: TM, 1998.

DELORY-MOMBERGER, C. Les histoires de vie: de l'invention de soi au projet de formation. Paris: Anthropos, 2004.

DOMINICÉ, P. Histoire de vie comme processus de formation. Paris: L'Harmattan, 2000.

FERRAROTTI, F. Sobre a autonomia do método biográfico. In: NÓVOA, A.; FINGER, M. 0 método (auto)biográfico e a formação. Lisboa: MS/DRHS/CFAP, 1988.

FONSECA, S. G. Ser professor no Brasil. Campinas: Papirus, 1997.

FONSECA, S. G. Aprender a contar, a ouvir, a viver: as narrativas como processo de formação. In: VEIGA, I. P. A. (Org.). Técnicas de ensino: novos tempos, novas configurações. Campinas: Papirus, 2006.

FREIRE, P. Educação é um ato político. Cadernos de Ciências, Brasília, n. 24, p. 21-22, jul./ago./set. 1991.

FREIRE, P. Pedagogia do oprimido. 50. ed. Rio de Janeiro: Paz e Terra, 2011.

FREIRE, P. Pedagogia da autonomia: saberes necessários à prática educativa. Rio de Janeiro: Paz e Terra, 1996.

FREIRE, P.; SHOR, I. Medo e ousadia. Rio de Janeiro: Paz e Terra, 1987.

GARCIA, C. M. Formação de professores: para uma mudança educativa. Porto: Porto Editora, 1999.

HALBWACHS, M. La mémorie collective. Paris, PUF, 1956.

JOSSO, M.-C. Experiências de vida e formação. Tradução de José Claudino e Júlia Ferreira. São Paulo: Cortez, 2005. 
LARROSA, J. Notas sobre narrativa e identidade. In: ABRAHÃO, M. H. M. B. (Org.). A aventura (auto)biográfica: teoria e empiria. Porto Alegre: EDIPUCRS, 2004.

ORLANDI, E. P. A linguagem e seu funcionamento: as formas do discurso. Em Aberto, Brasília, v. 14, n. 61, p. 53-59, 1994.

PESSOA, F. Poesias de Álvaro de Campos. Lisboa: Ática, 1993.

PIMENTA, S. G. Formação de professores: identidade e saberes da docência. In: PIMENTA, S. G. (Org.). Saberes pedagógicos e atividade docente. São Paulo: Cortez, 1999, p. 19-26.

PUIG, J. M. Ética e valores: métodos para um ensino transversal. São Paulo: Casa do Psicólogo, 1998.

NICOL, Eduardo. El porvenir de la filosofia. México: Fondo de Cultura: Económica, 1997.

NÓVOA, A.; FINGER, M. O método (auto)biográfico e a formação. Lisboa: MS/DRHS/CFAP, 1988.

NÓVOA, A. (Org.). Vidas de professores. Porto: Porto Editora, 1992a.

NÓVOA, A. (Org.). Os professores e sua formação. Lisboa: Dom Quixote, 1992b.

RIOS, T. Compreender e ensinar: por uma docência da melhor qualidade. São Paulo: Cortez, 2001.

ROSA, J. G. Estas estórias. 3. ed. Rio de Janeiro: Nova Fronteira, 1985.

ROSA, J. G. Grande sertão: veredas. Rio de Janeiro: Nova Fronteira, 1986.

SOUSA, C. P. Percursos de formação nas memórias de docentes universitários: In: SOUSA, C. P. Educação e Linguagem, São Bernardo do Campo, ano 8, n. 11, p. 105-122, jan./jun. 2005.

SOUZA, E. C. de. $O$ conhecimento de si: estágio e narrativas de formação de professores. Rio de Janeiro: DP\&A; Salvador: UNEB, 2006.

TARDIF, M. Os professores enquanto sujeitos do conhecimento: subjetividade, prática e saberes do magistério. In: CANDAU, V. M. (Org.). Didática, currículo e saberes escolares. Rio de Janeiro: DP\&A, 2000.

Revisão gramatical do texto sob responsabilidade de: Rafael Abrahão

E-mail: rafael.ibrahim.oz@gmail.com 